\title{
Backstepping Adaptive Control of DFIG-Generators for Variable-Speed Wind Turbines
}

\author{
Badre Bossoufi ${ }^{1,2}$, Mohammed Karim ${ }^{2}$, Ahmed Lagrioui ${ }^{3}$, Mohammed Taoussi ${ }^{2}$, Madiha El \\ Ghamrasni $^{3}$ \\ ${ }^{1}$ Laboratory of Electrical Engineering and Maintenance, Higher School of Technology, EST-Oujda, University \\ of Mohammed I, Morocco. \\ ${ }^{2}$ STIC Team, Faculty of Sciences Dhar El Mahraz, Sidi Mohamed Ben Abdellah University, Fez, Morocco \\ ${ }^{3}$ Mohammadia School of Engineering- BP 767 Agdal- Rabat -Morocco \\ Corresponding author: Badre_isai@hotmail.com
}

\section{ABSTRACT}

In this paper, we present a nonlinear robust control of active and reactive power by the use of the technique Backstepping a double-fed asynchronous generator (DFIG) system incorporated in a wind. The power transfer between the stator and the network is carried out by acting on the rotor via a bidirectional signal converter.

Initially, a control strategy of the MPPT asynchronous double fed generator is presented. Thereafter, a new control technique for wind systems is presented. This control scheme is based on an adaptive pole placement control strategy integrated to a Backstepping control scheme. The overall stability of the system is shown using Lyapunov technique. The performance and robustness are analyzed and compared by simulation based Matlab / Simulink software.

\section{Indexing terms/Keywords}

FPGA, Indirect Sliding Mode Control; Permanent Magnet Synchronous Machine (PMSM); Power System Control, Systems Generator; Reusability; PWM.

\section{SUBJECT CLASSIFICATION}

Revewlable Energies / Network Modeling and Simulation

\section{Council for Innovative Research}

Peer Review Research Publishing System

Journal: International Journal of Computers \& Technology

Vol 12, No.7

editor@cirworld.com

www.cirworld.com, member.cirworld.com 


\section{INTRODUCTION}

Today, wind energy has become a viable solution for the production of energy, in addition to other renewable energy sources. While the majority of wind turbines are fixed speed, the number of variable speed wind turbines is increasing [1]. The Doubly-Fed Asynchronous Generator (DFIG) with Backstepping control is a machine that has excellent performance and is commonly used in the wind turbine industry [2-3]. There are many reasons for using an Doubly-Fed Asynchronous Generator (DFIG) for wind turbine a variable speed, such as reducing efforts on mechanical parts, noise reduction and the possibility of control of active power and reactive.

The wind system using DFIG generator and a "back-to-back" converter that connects the rotor of the generator and the network has many advantages. One advantage of this structure is that the power converters used are dimensioned to pass a fraction of the total system power [5-6]. This allows reducing losses in the power electronics components. The performances and power generation depends not only on the DFIG generator, but also the manner in which the two parts of "back-to-back" converter are controlled.

The power converter machine side is called "Rotor Side Converter" (RSC) and the converter Grid-side power is called "Grid Side Converter" (GSC). The RSC converter controls the active power and reactive power produced by the machine. As the GSC converter, it controls the DC bus voltage and power factor network side.

The not adaptive backstepping approach offers a choice of design tools for accommodation of uncertainties nonlinearities. And can avoid wasteful cancellations. However, the not adaptive backstepping approach is capable of keeping almost all the robustness properties of the mismatched uncertainties. The not adaptive backstepping is a rigorous and procedure design methodology for nonlinear feedback control. The principal idea of this approach is to recursively design controllers for machine torque constant uncertainty subsystems in the structure and "step back" the feedback signals towards the control input. This approach is different from the approach of the conventional feedback linearization in that it can avoid cancellation of useful nonlinearities in pursuing the objectives of stabilization and tracking. A nonlinear backstepping control design scheme is developed for the speed tracking control of DFIG that has exact model knowledge. The asymptotic stability of the resulting closed loop system is guaranteed according to Lyapunov stability theorem.

The adaptive backstepping design offers a choice of design tools for accommodation of uncertainties nonlinearities. And can avoid wasteful cancellations. In addition, the adaptive backstepping approach [12] is capable of keeping almost all the robustness properties of the mismatched uncertainties. The adaptive backstepping is a systematic and recursive design methodology for nonlinear feedback control.

The Backstepping control is a systematic and recursive design methodology for nonlinear feedback control. Appling those design methods, control objectives such as position, velocity can be achieved.

A nonlinear backstepping control design scheme is developed for the speed tracking control of DFIG that has exact model knowledge. The asymptotic stability of the resulting closed loop system is guaranteed according to Lyapunov stability theorem.

In this paper, we present a technique to control two power converters which is based on the backstepping control. We analyze their dynamic performances by simulations in Matlab/Simulink environment. We start by modeling of the wind turbine, and then a tracking technique operating point at maximum power point tracking (MPPT) will be presented. Thereafter, we present a model of the DFIG in the dq reference, and the general principle of control of both power converters which is based on backstepping technique.

Considering the complexity of the diversity of the electric control devices of the machines, it is difficult to define with universal manner a general structure for such systems. However, by having a reflexion compared to the elements most commonly encountered in these systems, it is possible to define a general structure of an electric control device of machines which is show in Fig.1:

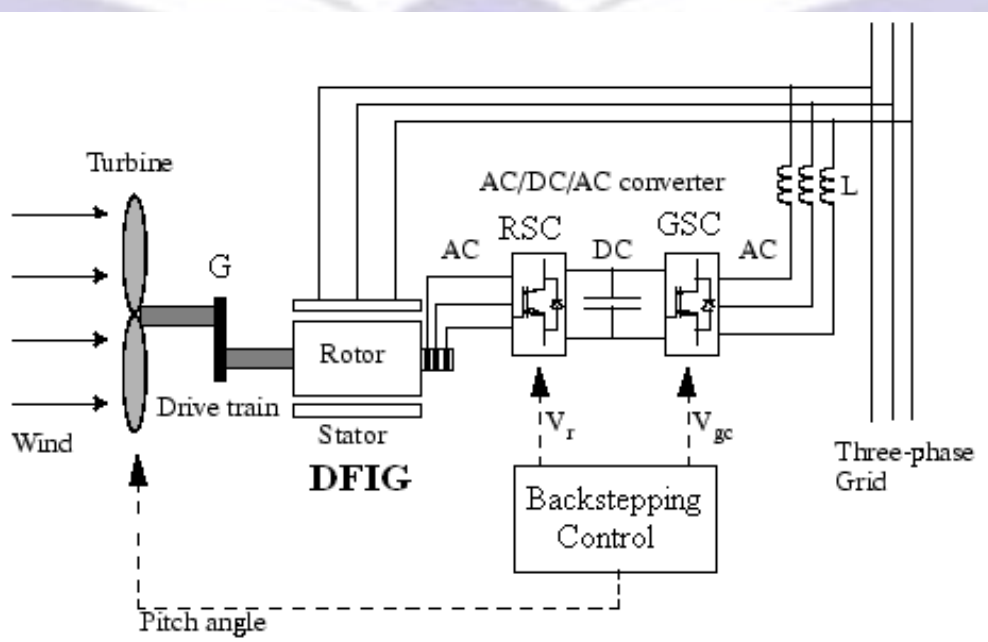

Fig.1: Architecture of the Control 


\section{MODELLING OF THE WIND-TURBINE}

By applying the theory of momentum and Bernoulli's theorem, we can determine the incident power (theoretical power) due to wind [7-8]:

$$
P_{\text {incident }}=\frac{1}{2} \cdot \rho \cdot S \cdot v^{3}
$$

$S:$ the area swept by the pales of the turbine $\left[\mathrm{m}^{2}\right]$

$\rho$ : the density of the air $\left(\rho=1.225 \mathrm{~kg} / \mathrm{m}^{3}\right.$ at atmospheric pressure).

$v$ : wind speed $[\mathrm{m} / \mathrm{s}]$

In wind energy system due to various losses, available on the power extracted from the turbine rotor, is lower than the incident power. The power extracted is expressed by [9]:

$$
P_{\text {extracted }}=\frac{1}{2} \cdot \rho \cdot S \cdot C_{p}(\lambda, \beta) \cdot v^{3}
$$

$\mathrm{Cp}(\lambda, \beta)$ is called the power coefficient, which expresses the aerodynamic efficiency of the turbine. It depends on the ratio $\lambda$, which represents the ratio between the speed at the end of the blades and the wind speed and the angle of orientation of the blades $\beta$. The ratio $\lambda$ can be expressed by the following relation [9-10]:

$\lambda=\frac{\Omega_{t} \cdot R}{v}$

The maximum power coefficient Cp was determined by Albert Betz (1920) as follows [11]:

$$
C_{p}^{\max }(\lambda, \beta)=\frac{16}{27} \approx 0.593
$$

The power factor is intrinsic to the constitution of the wind-turbine and depends on the profiles of the blades. We can model the power coefficient with a single equation that depends on the speed ratio $\lambda$ and pitch angle $\beta$ for the blade [12]:

$$
C_{p}(\lambda, \beta)=c_{1} \cdot\left(c_{2} \cdot \frac{1}{A}-c_{3} \cdot \beta-c_{4}\right) \cdot e^{-c_{5} \frac{1}{A}}+c_{6} \cdot \lambda
$$

$c_{1}=0.5872, c_{2}=116, c_{3}=0.4, c_{4}=5, c_{5}=21, c_{6}=0.0085$

The six coefficients $c_{1}, c_{2}, c_{3}, c_{4}, c_{5}$ are modified for maximum $\mathrm{Cp}$ equal to 0.498 for $\beta=0^{\circ}$.

With $A$ which depends on $\lambda$ and $\beta$ :

$\frac{1}{A}=\frac{1}{\lambda+0.08 . \beta}-\frac{0.035}{1+\beta^{3}}$

The Fig. 2 shows the curves of the power coefficient as a function of $\lambda$ for different values of $\beta$. A coefficient of maximum power of 0.498 is obtained for a speed ratio $\lambda$ which is 8 ( $\lambda$ opt). Fixing $\beta$ and $\lambda$ respectively to their optimal values, the wind system provides optimal power. 


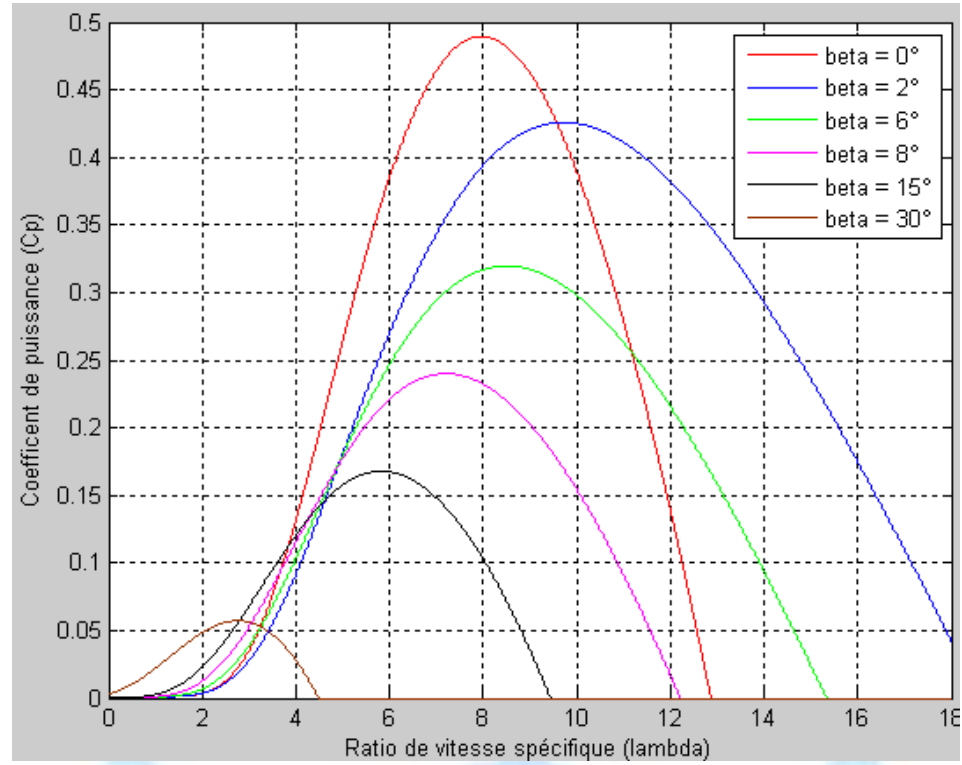

Fig.2: Power coefficient as a function of $\lambda$ and $\beta$

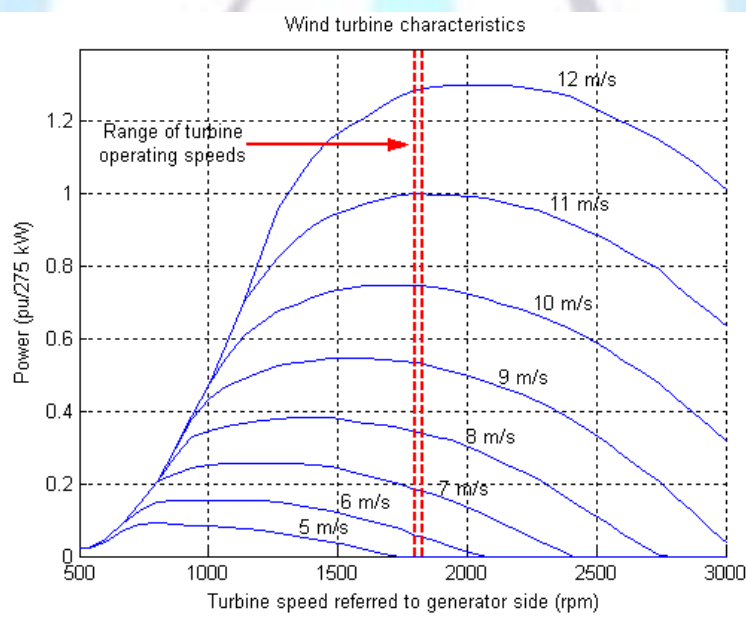

Fig.3: Wind-turbine DFIG characteristics

The aerodynamic torque on the slow axis can be expressed by Equation 7: [10]

$$
C_{a l}=\frac{P_{e o l}}{\Omega_{t}}=\frac{1}{2} \cdot \rho \cdot S \cdot C_{p}(\lambda, \beta) \cdot v^{3} \cdot \frac{1}{\Omega_{t}}
$$

\section{$\Omega_{t}:$ Rotational speed of the turbine}

$C_{a l}:$ Torque on the slow axis (turbine side)

The mechanical speed is related to the speed of rotation of the turbine by the coefficient of the multiplier. The torque on the slow axis is connected to the torque on the fast axis (generator side) by the multiplier coefficient. [10]:

The total inertia $\mathrm{J}$ is formed of the reduced inertia of the turbine and the fast axis of the inertia $\mathrm{J}$ of the generator $\mathrm{g}$

$J=\frac{J_{t u r}}{G^{2}}+J_{g}$

$J_{\text {tur }}$ : turbine inertia

$J_{g}:$ inertia of the generator.

To determine the evolution of the mechanical speed from $\mathrm{C}_{\text {mec }}$ total torque applied to the rotor of the DFIG, we apply the fundamental equation of dynamics: 
$J \frac{d \Omega_{m e c}}{d t}=C_{m e c}=C_{a r}-C_{e m}-f . \Omega_{m e c}$

$\Omega_{m e c}:$ Mechanical speed of DFIG

$C_{a r}$ : Aerodynamic torque on the fast axis of the turbine

$C_{e m}$ : Electromagnetic torque

\section{$f$ : Friction.}

The above equations are used to prepare the block diagram of the model of turbine (Fig.4).

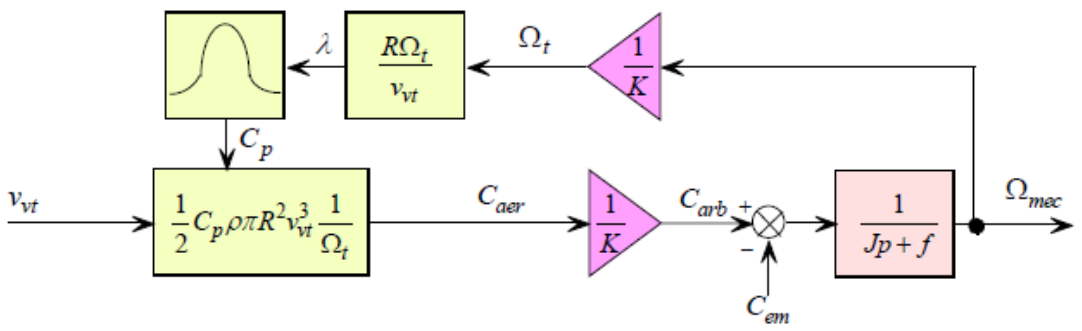

Fig.4: Wind-turbine model

\section{EXTRACTION OF MAXIMUM POWER}

In order to capture the maximum power of the incident energy of the wind-turbine, must continuously adjust the rotational speed of the wind turbine. The optimal mechanical turbine speed corresponds has $\lambda$ opt and $\beta=0^{\circ}$. The speed of the DFIG is used as a reference value for a controller proportional-integral type (PI phase advance). The latter determines the control set point which is the electromagnetic torque that should be applied to the machine to run the generator at its optimal speed.

The torque thus determined by the controller is used as a reference torque of the turbine model (Fig.5). The system of variation of the angle of orientation of the blades (variation of the angle of incidence) to change the ratio between the lift and drag. To extract the maximum power (and maintain constant), the adjusted angle of incidence of the blades to the wind speed.

The "Pitch Control" is a technique that mechanically adjusts the blade pitch angle to shift the curve of the power coefficient of the turbine [13].

However, it is quite expensive and is generally used for wind turbines and high average power. For our model, the "Stall Control" technique, which is a passive technique that allows a natural aerodynamic stall (loss of lift when the wind speed becomes more important). La régulation de la vitesse de rotation de l'angle de pas des pales de la turbine se produit lorsque la vitesse de la génératrice est supérieure à $30 \%$ de sa vitesse nominale. Otherwise, $\beta$ is zero. The synthesis of the $\mathrm{PI}$ controller requires knowledge of the transfer function of our system. This is especially difficult because of the power coefficient. A simple proportional correction $(P)$ is obtained after testing. Note that $\beta$ may vary from $0{ }^{\circ}$ to $90^{\circ}$ characterized by saturation.

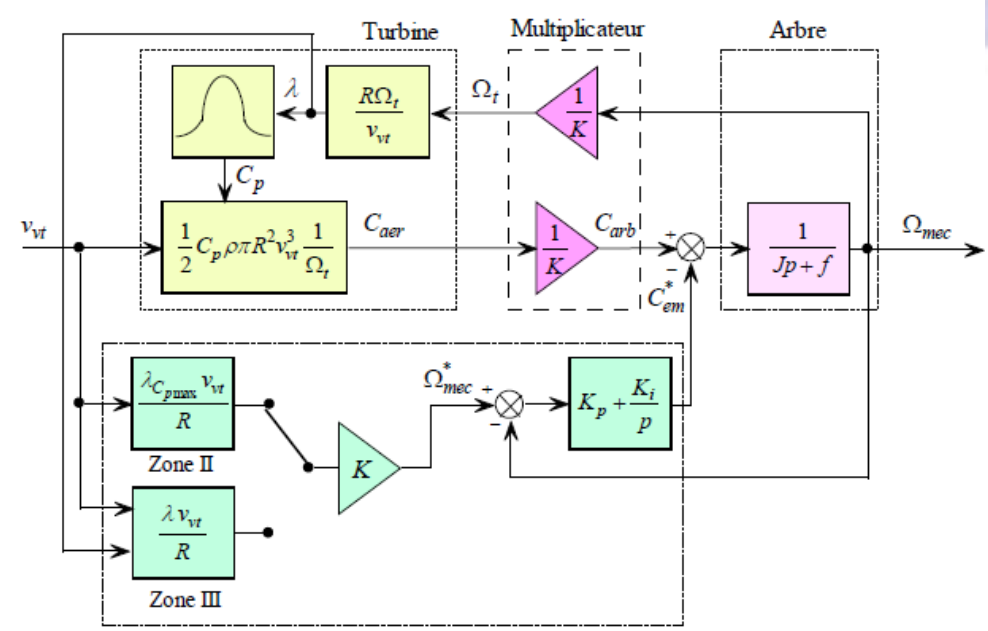

Fig.5: Block diagram with control of the speed 


\section{DFIG MODEL SYSTEM}

The Power equations in the dq reference DFIG can be written [10-14]:

$\left\{\begin{array}{l}v_{d s}=R_{s} \cdot i_{d s}+\frac{d}{d t} \phi_{d s}-\omega_{s} \cdot \phi_{q s} \\ v_{q s}=R_{s} \cdot i_{q s}+\frac{d}{d t} \phi_{q s}+\omega_{s} \cdot \phi_{d s} \\ v_{d r}=R_{r} \cdot i_{d r}+\frac{d}{d t} \phi_{d r}-\omega_{s} \cdot \phi_{q r} \\ v_{q r}=R_{r} \cdot i_{q r}+\frac{d}{d t} \phi_{q r}+\omega_{r} \cdot \phi_{d r}\end{array}\right.$

With:

$\omega_{r}=\omega_{s}-P . \Omega$

$\left\{\begin{array}{l}\phi_{d s}=L_{s} \cdot i_{d s}+M \cdot i_{d r} \\ \phi_{q s}=L_{s} \cdot i_{q s}+M i_{q r} \\ \phi_{d r}=L_{r} \cdot i_{d r}+M \cdot i_{d s} \\ \phi_{q r}=L_{r} \cdot i_{q r}+M \cdot i_{q s}\end{array}\right.$

$L_{s}=l_{s}-M_{s}, \quad L_{r}=l_{r}-M_{r}$

$L_{s}, L_{r}$ : Cyclic inductances of stator and rotor phase;

$I_{s}, I_{r}:$ Inductances of stator and rotor phase;

$M_{s}, M_{r}$ : Mutual inductances between stator and rotor phases respectively;

M: Maximum mutual inductance between stator and rotor stage (the axes of the two phases coincide).

The expression of the electromagnetic torque of the DFIG depending on flow and stator currents can be written as follows:

$C_{e m}=P\left(\phi_{d s} \cdot i_{q s}-\phi_{q s} \cdot i_{d s}\right)$

With P: number of pole pairs of the DFIG.

The active and reactive powers stator and rotor of the DFIG are written as follows [10-14]:

$\left\{\begin{array}{l}P_{s}=v_{d s} \cdot i_{d s}+v_{q s} \cdot i_{q s} \\ Q_{s}=v_{q s} \cdot i_{d s}-v_{d s} \cdot i_{q s} \\ P_{r}=v_{d r} \cdot i_{d r}+v_{q r} \cdot i_{q r} \\ Q_{r}=v_{q r} \cdot i_{d r}-v_{d r} \cdot i_{q r}\end{array}\right.$ 


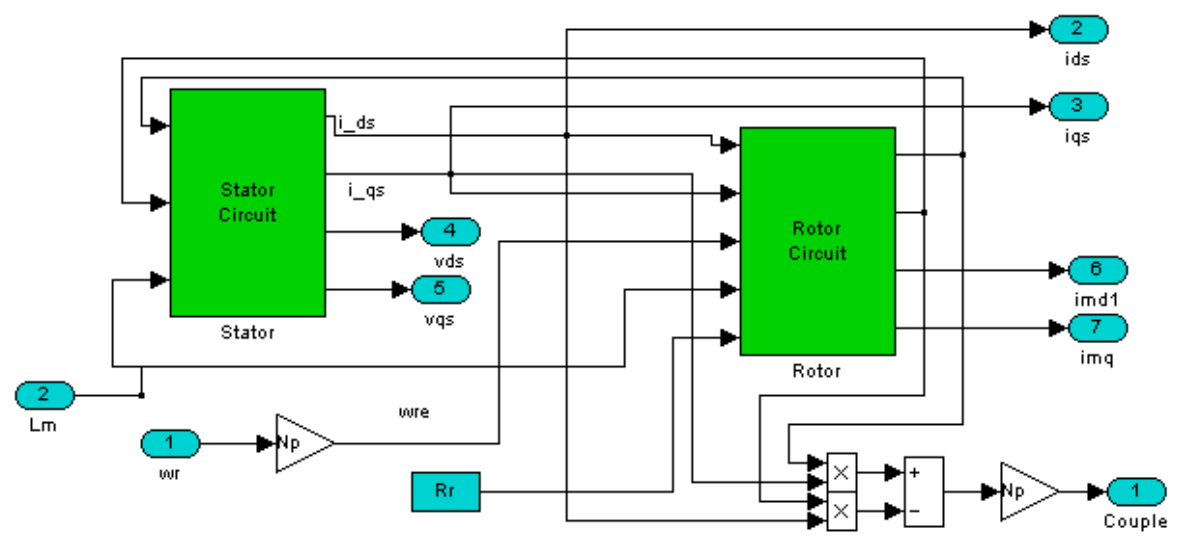

Fig.6: DFIG Model for wind-turbine

\section{BACKSTEPPING ADAPTATIVE CONTROLLER APPLIED TO DFIG GENERATOR}

The Adaptive Backstepping Control is a control technique that can effectively linearize a nonlinear system such as the DFIG in the presence of uncertainties. Unlike other feedback linearization techniques, adaptive backstepping has the flexibility of keeping useful non linearity's intact during stabilization. The essence of backstepping is the stabilization of a virtual control state. Hence, it generates a corresponding error variable which can be stabilized by carefully selecting proper control inputs. These inputs can be determined from Lyapunov stability analysis.

From (10), it is obvious that the dynamic model of PMSM is highly nonlinear because of the coupling between the speed and the electrical currents. According to the vector control principle, the direct axis current $i_{d}$ is always forced to be zero in order to orient all the linkage flux in the $d$ axis and achieve maximum torque per ampere.

$$
\begin{aligned}
& \frac{d i_{s d}}{d t}=-\frac{r_{s}}{L_{s d}} i_{s d}+\frac{L_{s q}}{L_{s d}} p \Omega i_{s q}+\frac{V_{s d}}{L_{s d}} \\
& \frac{d i_{s q}}{d t}=-\frac{r_{s}}{L_{s q}} i_{s q}-\frac{L_{s d}}{L_{s q}} p \Omega i_{s d}-\frac{\Phi_{f}}{L_{s q}} p \Omega+\frac{V_{s q}}{L_{s q}} \\
& \frac{d \Omega}{d t}=\frac{3 p}{2 J}\left(\Phi_{f} i_{s q}+\left(L_{s d}-L_{s q}\right) i_{s d} i_{s q}\right)-\frac{f}{J} \Omega+\frac{C_{r}}{J}
\end{aligned}
$$

The vector $[x]=\left[\begin{array}{lll}x_{1} & x_{2} & x_{3}\end{array}\right]^{T}=\left[\begin{array}{lll}i_{s d} & i_{s q} & \Omega\end{array}\right]^{T}$ choice as state vector is justified by the fact that currents and speed are measurable and that the control of the instantaneous torque can be done comfortable via the currents $i_{s d}$ and/or $i_{s q}$ And stator voltages as control variables $u=\left[\begin{array}{ll}V_{s d} & V_{s q}\end{array}\right]^{T}$.

The main objective of the backstepping control is to regulate the speed of the machine to its reference value $\Omega_{\text {ref }}$ whatever external disturbances.

It is assumed that the engine parameters are known and invariant.

By choosing $\left[\begin{array}{lll}i_{s d} & i_{s q} & \Omega\end{array}\right]^{T}$ as variable states and equation (14) the mathematical model of the machine. The objective is to regulate the speed to its reference value.

\subsection{Backstepping speed Controller}

We begin by defining the tracking errors:

$e_{\Omega}=\Omega_{r e f}-\Omega$

The derivative of (15) is:

$\dot{e}_{\Omega}=\frac{d e_{\Omega}}{d t}=\dot{\Omega}_{r e f}-\dot{\Omega}=\dot{\Omega}_{r e f}-\frac{1}{J}\left[\frac{3 p}{2}\left(\Phi_{f} i_{s q}+\left(L_{s d}-L_{s q}\right) i_{s d} i_{s q}\right)-f \Omega-C_{r}\right]$ 
We define the following quadratic function:

$V_{1}=\frac{1}{2} e_{\Omega}^{2}$

Its derivative along the solution of (17), is given by:

$\dot{V}_{1}=e_{\Omega} \dot{e}_{\Omega}=e_{\Omega}\left(\dot{\Omega}_{r e f}-\frac{1}{J}\left[\frac{3 p}{2}\left(\Phi_{f} i_{s q}+\left(L_{s d}-L_{s q}\right) i_{s d} i_{s q}\right)-f \Omega-C_{r}\right]\right)$

Using the backstepping design method, we consider the d-q axes currents components $i_{s d}$ and $i_{s q}$ as our virtual control elements and specify its desired behavior, which are called stabilizing function in the backstepping design terminology as follows:

$$
\left\{\begin{array}{l}
i_{\text {sdref }}=0 \\
i_{\text {sqref }}=\frac{2}{3 p \Phi_{f}}\left(f \Omega+C_{r}+J \cdot k_{\Omega} . e_{\Omega}\right)
\end{array}\right.
$$

Where $k_{\Omega}$ is a positive constant

Substituting (19) in (18) the derivative of $V_{1}$ :

$\dot{V}_{1}=-k_{\Omega} e_{\Omega}^{2} \leq 0$

\subsection{Backstepping Current controller}

We have the asymptotic stability of the origin of the system (14). We defined:

$$
\left\{\begin{array}{l}
e_{d}=i_{s d r e f}-i_{s d} \quad \text { with } i_{s d r e f}=0 \\
e_{q}=i_{s q r e f}-i_{s q}
\end{array}\right.
$$

Their dynamics can be written:

$$
\begin{aligned}
& \dot{e}_{d}=\dot{i}_{s d r e f}-\dot{i}_{s d}=\frac{r_{s}}{L_{s d}} \cdot i_{s d}-\frac{L_{s q}}{L_{s d}} p \Omega i_{s q}-\frac{V_{s d}}{L_{s d}} \\
& \dot{e}_{q}=\dot{i}_{s q r e f}-\dot{i}_{s q}=\frac{2}{3 p \Phi}\left(f \Omega+C_{r}+J \cdot k_{\Omega} \cdot e_{\Omega}\right)+\frac{r_{s}}{L_{s q}} \cdot i_{s q}+\frac{L_{s d}}{L_{s q}} p \Omega i_{s d}+\frac{p \Phi}{L_{s q}} \Omega-\frac{V_{s d}}{L_{s d}}
\end{aligned}
$$

To analyze the stability of this system we propose the following Lyapunov function:

$$
V_{2}=\frac{1}{2}\left(e_{\Omega}^{2}+e_{d}^{2}+e_{q}^{2}\right)
$$

Its derivative along the trajectories (20), (21) and (22) is: 


$$
\begin{aligned}
& \dot{V}_{2}=\frac{1}{2}\left(e_{\Omega} \dot{e}_{\Omega}+e_{d} \dot{e}_{d}+e_{q} \dot{e}_{q}\right) \\
& =-k_{\Omega} e_{\Omega}^{2}-k_{d} e_{d}^{2}-k_{q} e_{q}^{2}+e_{d}\left[k_{d} e_{d}-\frac{V_{s d}}{L_{s d}}+\frac{r_{s}}{L_{s d}}-\frac{L_{s q}}{L_{s d}} \Omega i_{s q}+\frac{3 p}{2 J}\left(L_{s d}-L_{s q}\right) e_{\Omega} i_{s q}\right] \\
& +e_{q}\left[k_{q} e_{q}+\frac{2\left(k_{\Omega} J-f\right)}{3 p \Phi_{f}} \cdot\left(\frac{3 p \Phi_{f}}{2 J} e_{q}+\frac{3 p}{2 J}\left(L_{s d}-L_{s q}\right) e_{d} i_{s q}-k_{\Omega} e_{\Omega}\right)\right. \\
& \left.+\frac{3 p \Phi_{f}}{2 J} e_{\Omega}-\frac{V_{s q}}{L_{s q}}+\frac{r_{s}}{L_{s q}} i_{s q}+\frac{L_{s d}}{L_{s q}} \Omega i_{s d}+\Omega \frac{\Phi_{f}}{L_{s q}}\right]
\end{aligned}
$$

The expression (24) found above requires the following control laws:

$$
\begin{aligned}
& V_{s d}=k_{d} L_{s d} e_{d}+r_{s} i_{s d}-L_{s q} \Omega i_{s q}+\frac{3 p L_{s d}}{2 J}\left(L_{s d}-L_{s q}\right) e_{\Omega} i_{s q} \\
& V_{s q}=\frac{2 L_{s q}\left(k_{\Omega} J-f\right)}{3 p \Phi_{f}}\left(\frac{3 p \Phi_{f}}{2 J} e_{q}+\frac{3 p}{2 J}\left(L_{s d}-L_{s q}\right) e_{d} i_{s q}-k_{\Omega} e_{\Omega}\right)+\frac{3 p \Phi_{f} L_{s q}}{2 J} e_{\Omega}+r_{s} i_{s q}+L_{s d} \Omega i_{s d}+\Omega \Phi_{f}+k_{q} L_{s q} e_{q}
\end{aligned}
$$

With this choice the derivatives of (25) become:

$\dot{V}_{2}=-k_{\Omega} e_{\Omega}-k_{d} e_{d}-k_{q} e_{q} \leq 0$

\section{SIMULATION RESULTS}

The overall model of the wind system was simulated in Matlab/ Simulink/SimPowerSystems environment. The model includes: wind turbine, Doubly-Fed Asynchronous Generator (DFIG), two power converters that connect the rotor to the network (Figure 7).

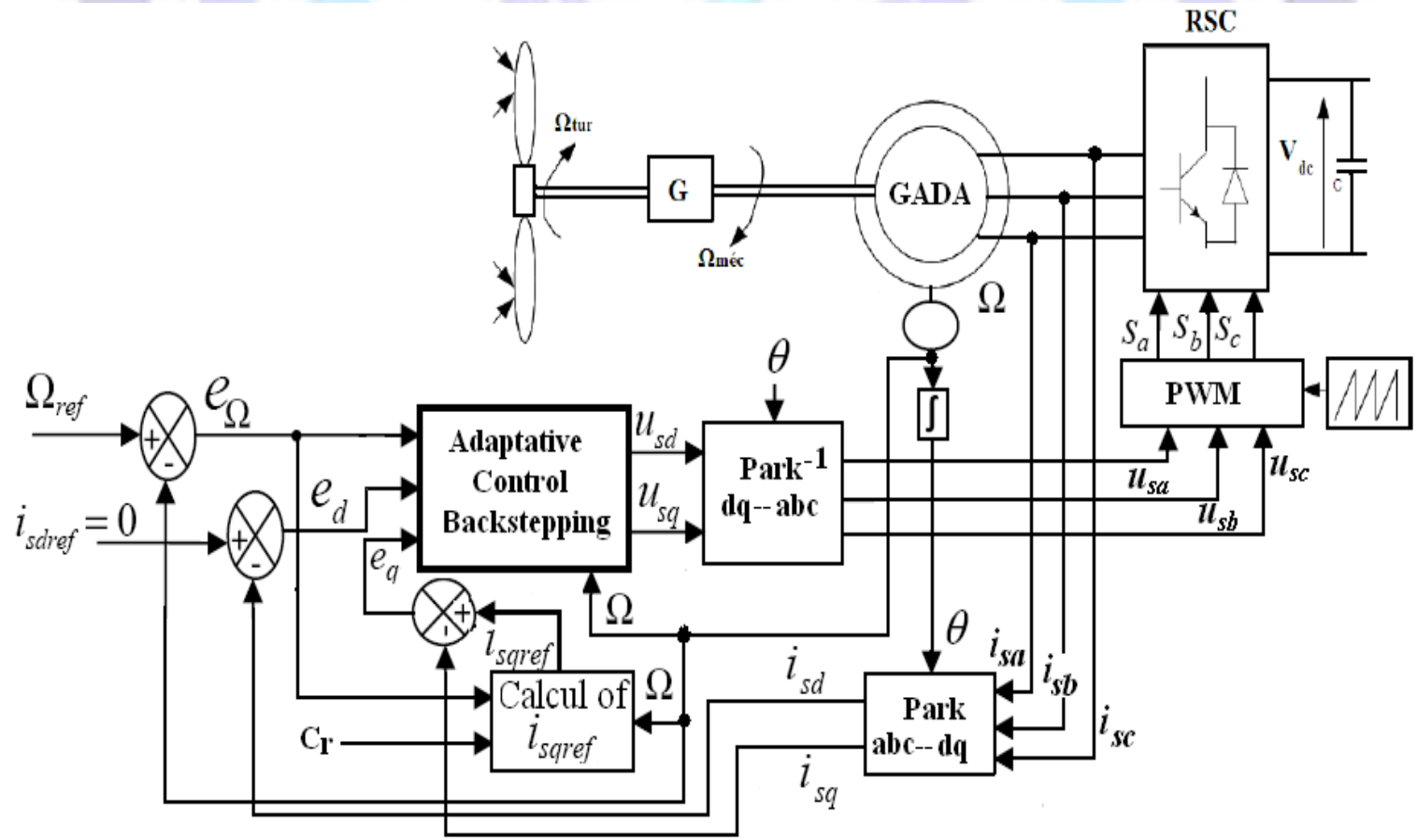

Fig.7: Simulation scheme of adaptive Backstepping Control applied for DFIG-wind-turbine

\subsection{DFIG performances}

The following results are obtained by choosing the following values:

$\checkmark$ Gains of the control law: $k_{\Omega}=0.15, k_{d}=0.01, k_{q}=0.01$. 
Adaptation gains: $\gamma_{1}=0.15, \gamma_{2}=0.01, \gamma_{3}=0.015$

Follow of the trajectory

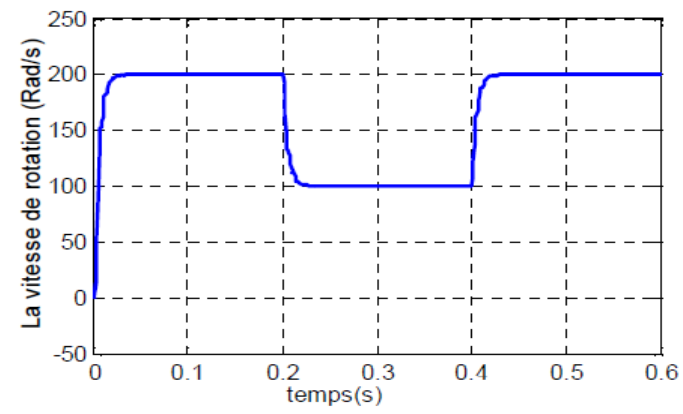

(a)

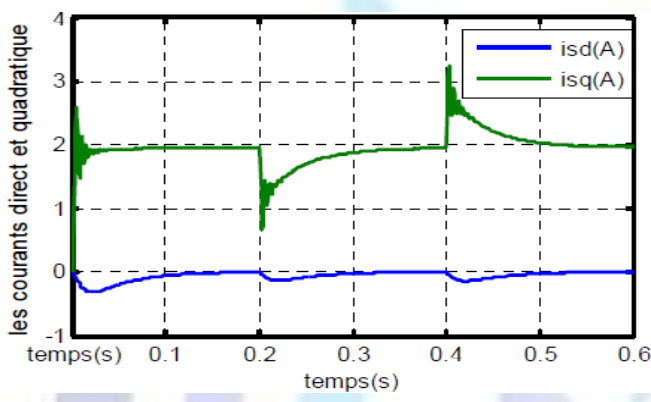

(c)

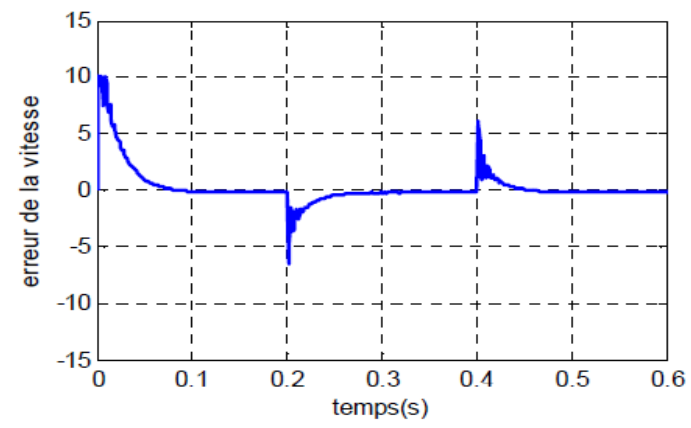

(b)

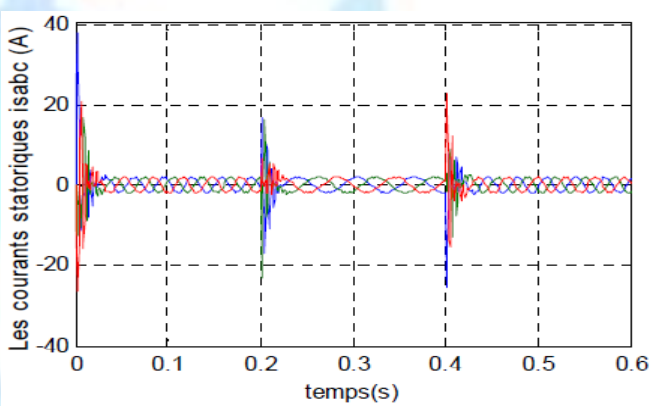

(d)

Fig.8: Test performance of the adaptive controller for trajectory tracking, (a) Speed response trajectory (b) Error Speed response (c) $d-q$ axis current without uncertainties (d) abc axis current

\section{Disturbance rejection}

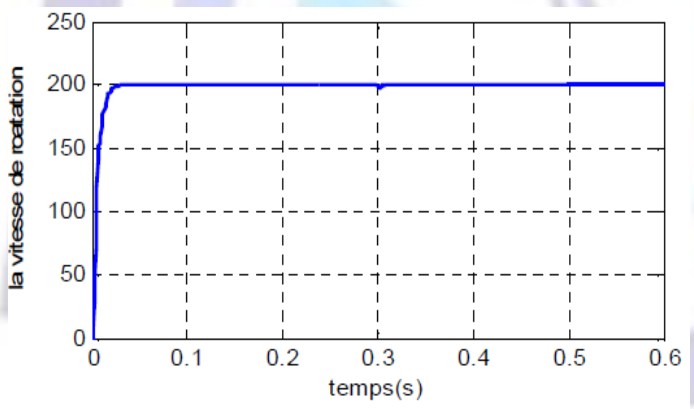

(a)

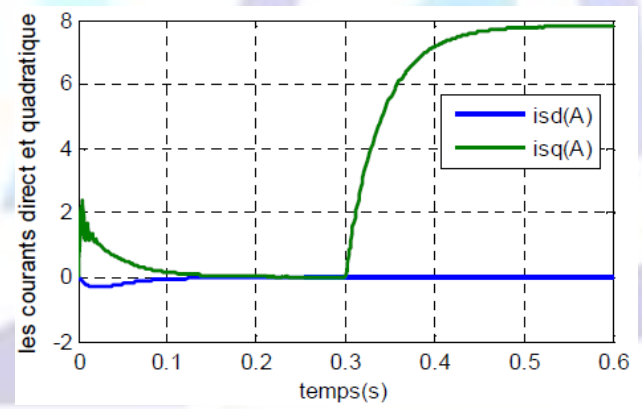

(b)

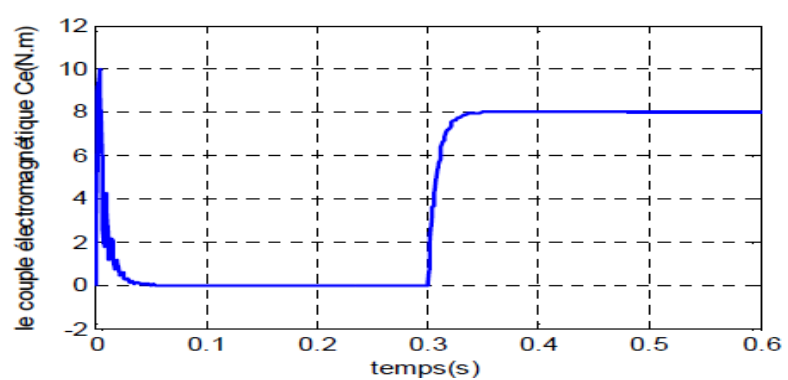

(c)

Fig.9: Test performance of the adaptive controller for rejecting disturbance torque load applied at $t=0.3 \mathrm{~s}$. (a)Speed response trajectory (b) $d-q$ axis current without uncertainties (c) Electromagnetic Torque 


\section{Parametric uncertainties}

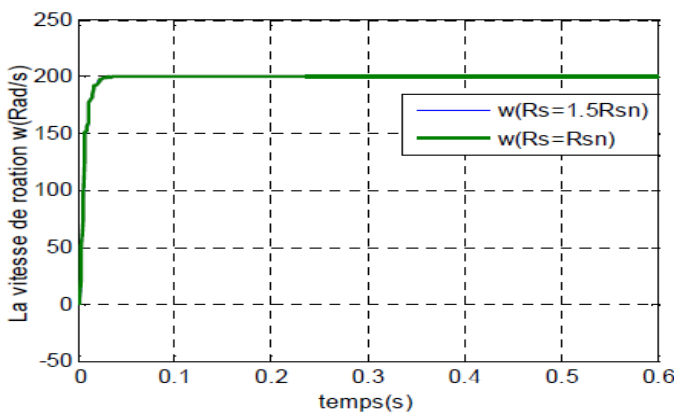

(a)

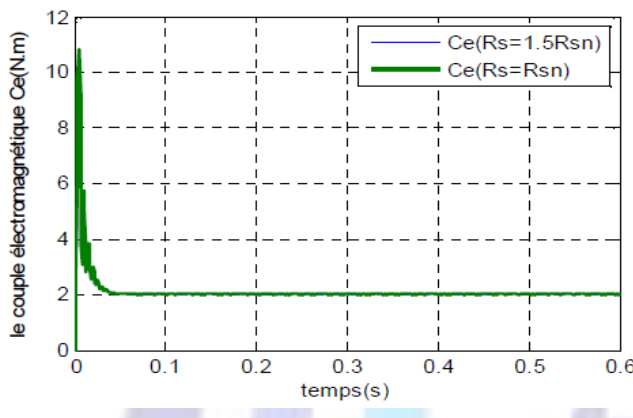

(c)

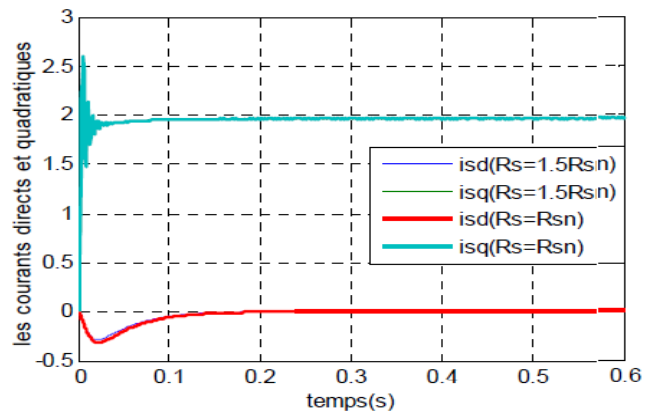

(b)

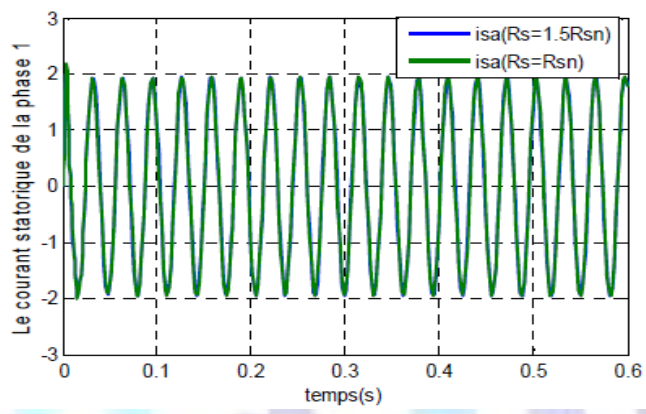

(d)

Fig.10: Test performance of the adaptive controller following a change in Rs. (a) Speed response trajectory (b) d-q axis current without uncertainties (c) Electromagnetic Torque (d) current isa

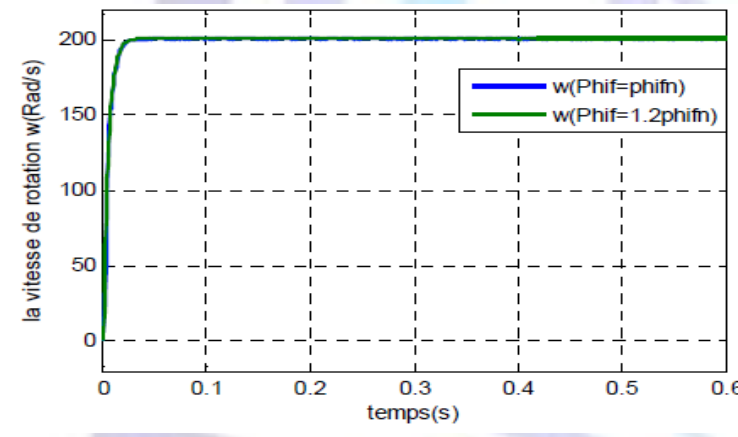

(a)

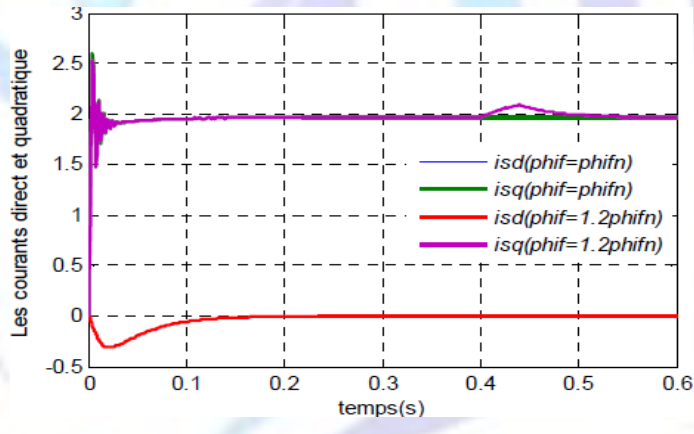

(b)

Fig.11: Test performance of the adaptive controller following a change in $\Phi_{f}$. (a) Speed response trajectory (b) d-q axis current without uncertainties

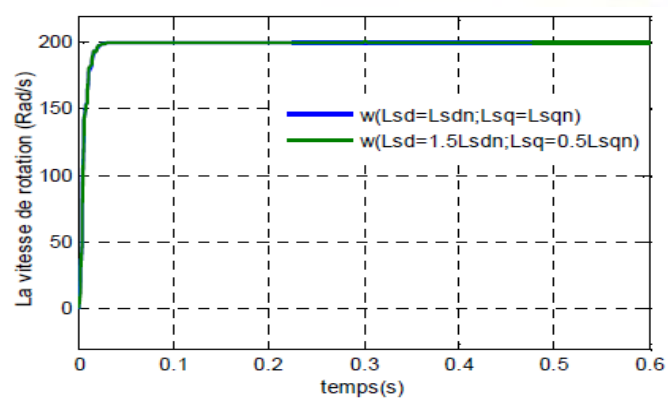

(a)

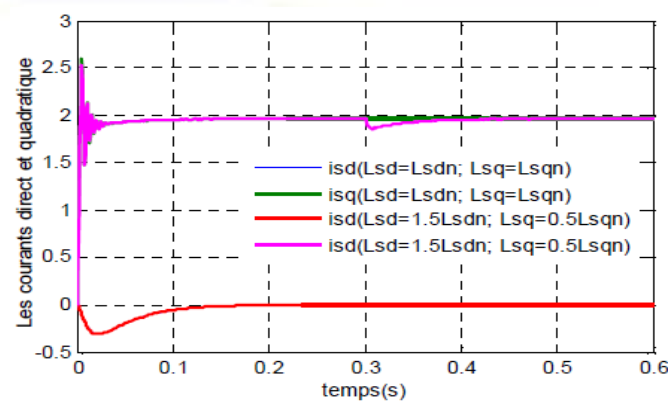

(b)

Fig.12: Test performance of the adaptive controller following a change in $L_{s d}$ and $L_{s q}$, (a) Speed response trajectory (b) $d-q$ axis current without uncertainties 


\subsection{Wind-turbine performances}

Using the reduced model, we applied a profile closer to the evolution of the real wind was filtered to suit the slow dynamics of the system studied random wind. The objective is to see the degree of continuing point of maximum power and efficiency of the speed control provided by the backstepping controller. The Fig.13 shows the wind profile filtered and applied to the system in this case.

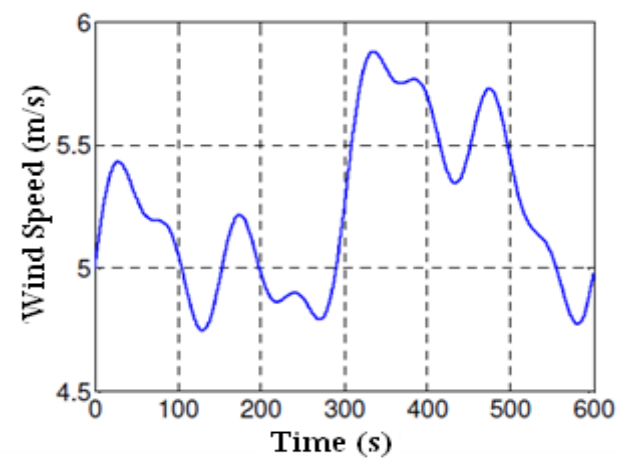

Fig. 13: Profile applied to random wind wind turbine.

The figure 14 shows the results obtained for this application, where the following observations can be distinguished:

$>$ The specific speed $\lambda$ and the power coefficient $C_{p}$ does not change a lot of values, they are almost equal to their optimal values references 9 and 0.4999 successively;

$>$ The wind power captured follows its optimal reference and has the same shape as the wind profile applied, this rate is also consistent with the wind torque side of the MADA;

$>$ The speed of the DFIG is the image of wind causing the wind, it properly follows its reference;

$>$ The shapes of the electromagnetic torque of the DFIG and its reference, are virtually identical, but different from the shape of the profile of the wind speed due to the dynamic torque due to inertia;

$>$ The phase shift between the voltage $180^{\circ}$ and the stator current phase reflects a production of active power only to the stator as illustrated in figure powers;

$>$ The shape of the components of the stator flux orientation shows a good flow to ensure vector control well decoupled from the DFIG.
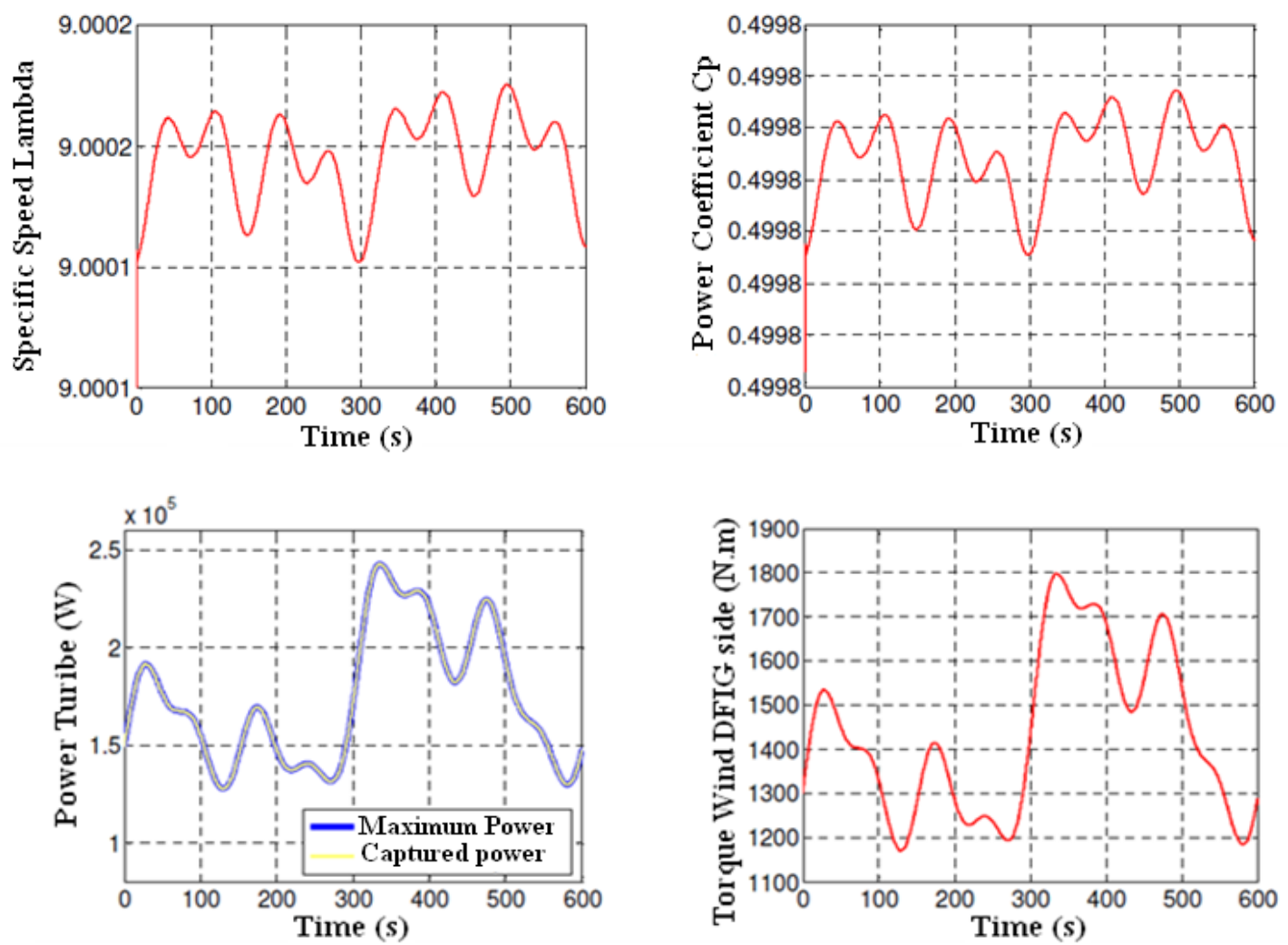

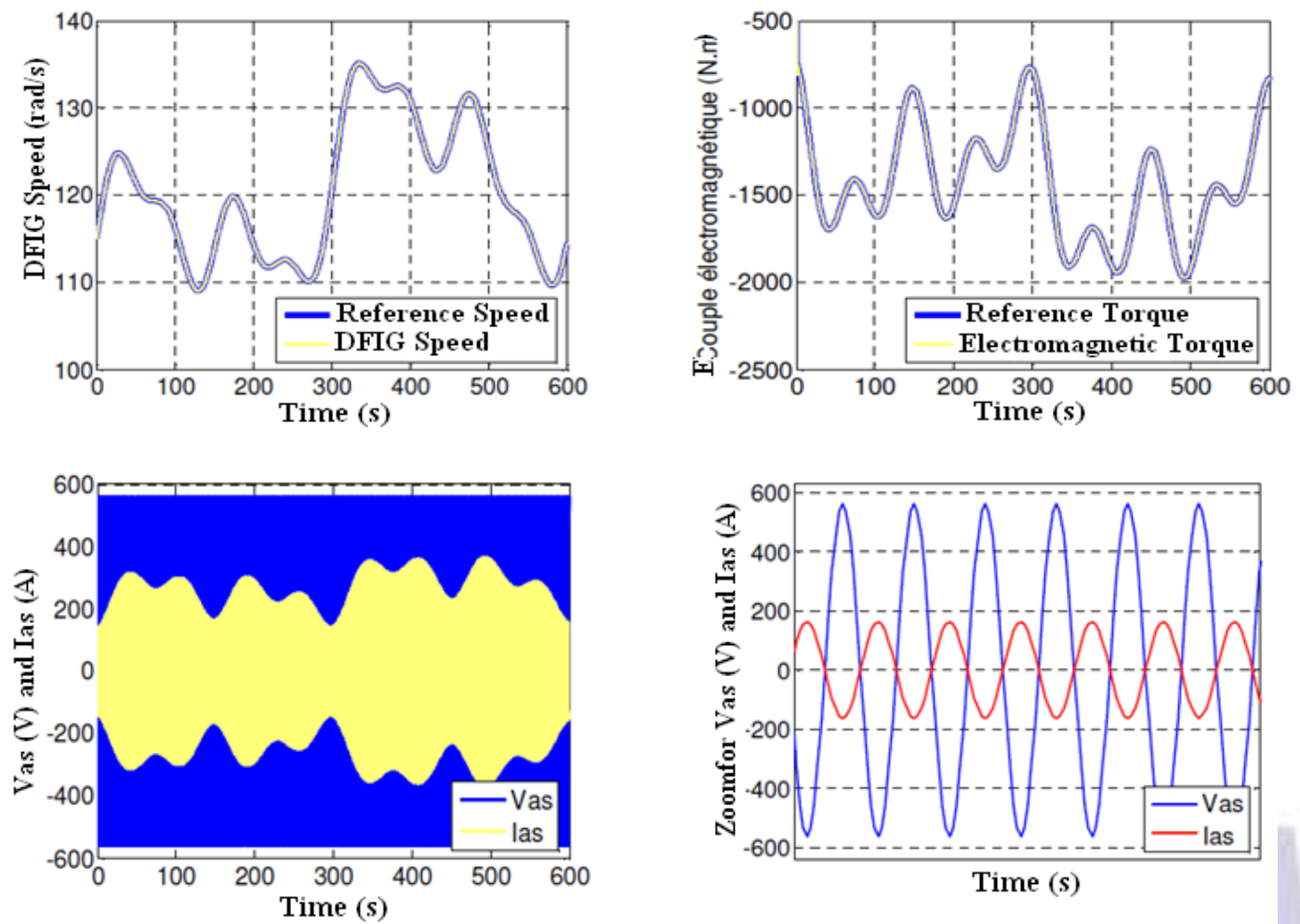

Time (s)
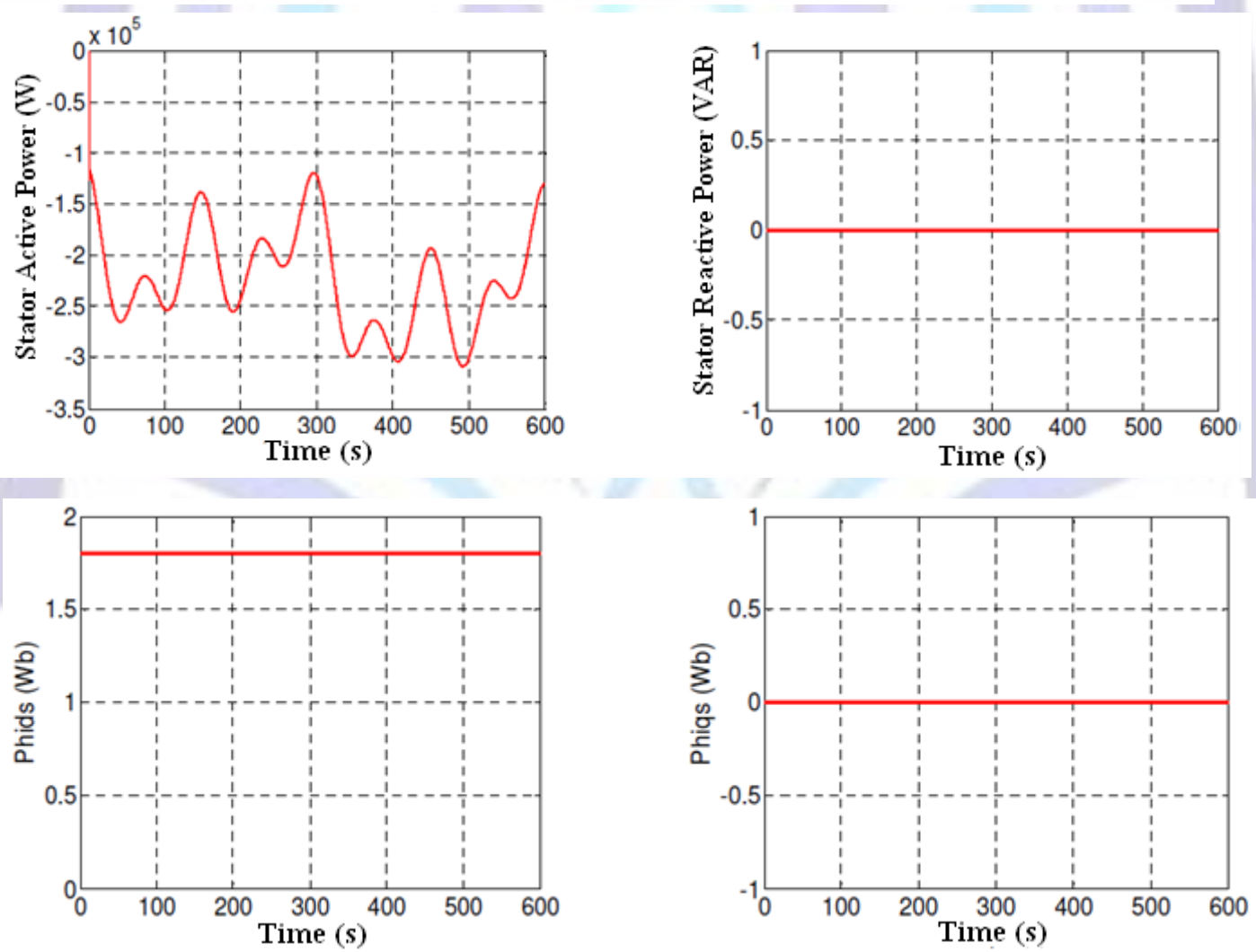

Fig.14: The Simulation results of the asynchronous wind generator dual power and stator flux oriented, with a Backstepping controller (Case scale model of the DFIG and profile of random wind). 


\section{CONCLUSION}

This work has been devoted to modeling, simulation and analysis of a wind turbine operating at variable speed. A stable operation of the wind energy system is obtained with the application of nonlinear Backstepping Adaptive control. The overall operation of the wind turbine and its control system were illustrated by responses to transient and permanent control systems.

Generator supplied power to the network with an active power whatever the mode of operation. The wind generator has been tested and modeled with a variable speed operation for a power of $200 \mathrm{~kW}$. Simulation results show that the proposed wind system and is feasible and has many advantages.

\section{REFERENCES}

[1] T. Ackermann and Soder, L. « An Overview of Wind Energy-Status 2002 ». Renewable and Sustainable Energy Reviews 6(1-2), 67-127 (2002).

[2] T. Burton, D. Sharpe, N. Jenkins and E. Bossanyi, Wind Energy Handbook. John Wiley\&Sons, Ltd, 2001.

[3] W. L. Kling and J. G. Slootweg, «Wind Turbines as Power Plants». in Proceeding of the IEEE/Cigré workshop on Wind Power and the impacts on Power Systems, 17-18 June 2002, Oslo, Norway.

[4] D. Seyoum, C. Grantham, «Terminal Voltage Control of a Wind Turbine Driven Isolated Induction Generator using Stator Oriented Field Control». IEEE Transactions on Industry Applications, pp. 846-852, September 2003.

[5] A. DAVIGNY, Participation aux services système de fermes éoliennes à vitesse variable intégrant un stockage inertiel d'énergie, Thèse de Doctorat, USTL Lille (France), 2007.

[6] K. GHEDAMSI, Contribution à la modélisation et la commande d'un convertisseur direct de fréquence. Application à la conduite de la machine asynchrone, Thèse de Doctorat, ENP Alger (Algérie), 2008.

[7] B.Bossoufi, M.Karim, S.Ionita, A.Lagrioui, "Nonlinear Non Adaptive Backstepping with Sliding-Mode Torque Control Approach for PMSM Motor" Journal of Journal of Electrical Systems JES, pp236-248. Vol.8 No.2, June 2012.

[8] X. YU, K. STRUNZ, “ Combined long-term and shortterm access storage for sustainable energy system », 2004 IEEE Power Engineering Society General Meeting, vol.2, pp.1946-1951, 10 June 2004.

[9] S. E. Ben Elghali, « Modélisation et Commande d'une hydrolienne Equipée d'une génératrice Asynchrone Double Alimentation », JGGE’08, 16-17 Décembre 2008, Lyon (France).S

[10] E. AIMANI, Modélisation de différentes technologies d'éoliennes intégrées dans un réseau de moyenne tension, Thèse de Doctorat, École Centrale de Lille (France), 2004.

[11] X. YAO, C. YI, D. YING, J. GUO and L. YANG, « The grid-side PWM Converter of the Wind Power Generation System Based on Fuzzy Sliding Mode Control », Advanced Intelligent Mechatronics, IEEE 2008, Xian (Chine).

[12] B.Bossoufi, M.Karim, S.Ionita, A.Lagrioui, "DTC CONTROL BASED ARTIFICIAL NEURAL NETWORK FOR HIGH PERFORMANCE PMSM DRIVE" Journal of Theoretical and Applied Information Technology JATIT, pp165-176, Vol. 33 No.2, 30th November 2011.

[13] B.Bossoufi, M.Karim, S.Ionita, A.Lagrioui, "Indirect Sliding Mode Control of a Permanent Magnet Synchronous Machine: FPGA-Based Implementation with Matlab \& Simulink Simulation" Journal of Theoretical and Applied Information Technology JATIT, pp32-42, Vol. 29 No.1, 15th July 2011.

[14] N.SGHAIER, T.RAMZI, S.GDAIM, B.BOSSOUFI, M.F. MIMOUNI, "Backstepping control of induction motor using Xilinx System Generator: FPGA-based implementation", International Journal of Emerging Sciences" (IJES), pp289302, Vol.3 No.3, 1th September 2013

[15] N.SGHAIER, T.RAMZI, S.GDAIM, B.BOSSOUFI, M.F. MIMOUNI, "Vector control for induction motor with rotor flux oriented using Xilinx System Generator", Journal of Theoretical and Applied Information Technology JATIT, pp259 268, Vol. 54 No.2, 20th August 2013.

[16] B.BOSSOUFI, M.KARIM, S.IONITA, A.LAGRIOUI, "Nonlinear Non Adaptive Backstepping with Sliding-Mode Torque Control Approach for PMSM Motor" Journal of Journal of Electrical Systems JES, pp236-248. Vol.8 No.2, June 2012.

[17] B.BOSSOUFI, M.KARIM, A.LAGRIOUI, "Matlab \& Simulink Simulation with FPGA-Based Implementation adaptative and not adaptative backstepping nonlinear Control of a Permanent Magnet Synchronous Machine Drive" WSEAS TRANSACTIONS on SYSTEMS and CONTROL, Vol.9 No.1, March 2014.

[18] B.BOSSOUFI, M.KARIM, S.IONITA, A.LAGRIOUI, "The Optimal Direct Torque Control of a PMSM drive: FPGABased Implementation with Matlab \& Simulink Simulation" Journal of Theoretical and Applied Information Technology JATIT, pp63-72, Vol. 28 No.2, 30th June 2011.

[19] A. BOYETTE, Contrôle-commande d'un générateur asynchrone à double alimentation avec système de stockage pour la production éolienne, Thèse de Doctorat, Nancy (France), 2006. 
[20] B.Bossoufi, M.Karim, S.lonita, A.Lagrioui, "Low-Speed Sensorless Control of PMSM Motor drive Using a NONLINEAR Approach BACKSTEPPING Control: FPGA-Based Implementation" Journal of Theoretical and Applied Information Technology JATIT, pp154-166, Vol. 36 No.1, 29th February 2012.

[21] Hisn-Jang Shieh and Kuo-Kai Shyu, "Non Linear Sliding Mode Torque Control With Adaptive Backstepping Approach For Induction Motor Drive", IEEE Transactions on Industrial Electronics, Vol. 46, N² 2, April 1999, pp. 380-388.

[22] M. Rodic, K. Jezernik, "Speed Sensoless Sliding Mode Torque Control of Induction Motor ", IEEE Trans on. Industrial Electronics, February 2002.

[23] Melicio, R; Mendes, VMF; Catalao, JPS "Modeling, Control and Simulation of Full- Power Converter Wind Turbines Equipped with Permanent Magnet SynchronousGenerator" vol 5, pg 397-408 Mar - Apr 2010. 